\title{
Adverse Drug Reaction Reporting Bv Doctors in a Developing Country: a Case Study from Ghana
}

\author{
Article by Mark Korankye \\ M.Sc Clinical Research, Texila American University, Ghana \\ Email: marklister85@gmail.com
}

\begin{abstract}
This paper reviewed an original article written by Sabblah et al on the adverse drug reaction reporting by medical doctors in a region in Ghana in 2012 but article originally published in 2014.

All over the world, spontaneous adverse drug reaction reporting is the mostly used method of monitoring the safety of drugs. This method is challenged with underreporting by healthcare professionals. The original article seeks to assess the knowledge of doctors about the adverse drug reaction (ADR) reporting system in Ghana, the rate of reportage and the attitude of the doctors on spontaneous reporting of ADRs. The method used was a cross-sectional survey and a selfadministered questionnaire was used to collect data.

This review was to summarize and critique the content of the study and state possible recommendations. In critiquing, the authority, accuracy, currency and objectivity of the study were assessed. The study's relevance, stability and graphs/tables were also assessed. In the article there were no recommendations or limitation to the study itself, recommendations were however made for improving spontaneous reporting. The results cannot be generalized so further studies are recommended in a national scope.
\end{abstract}

Keywords: Ghana; spontaneous reporting; ADR; doctors; review; underreporting

\section{Source}

Sabblah GT, Akweongo P, Darko D, Dodoo AN, Sulley AM. (2014) Adverse drug reaction reporting by doctors in a developing country: a case study from Ghana: Ghana Medical Journal, December, Vol. 48, no. 4, pp189-193. Doi: 10.4314/gmj.v48i4.4. Accessed on 5th September 2016 at http://www.ajol.info/index.php/gmj/article/view/112883

\section{Introduction}

The article "Adverse drug reaction reporting by doctors in a developing country: a case study from Ghana" by Sabblah George et al. seeks to assess the knowledge of doctors about the adverse drug reaction (ADR) reporting system in Ghana and the rate of reportage. The study also sought to assess the attitude of the doctors on spontaneous reporting of ADRs.

This article was published in journal for doctors managed by Ghana Medical Association. It is the right journal for the impact needed for the ADR reporting advocacy. Spontaneous ADR reporting is a basic mechanism for pharmacovigilance and so reportage from doctors is quite significant. A reportage of 6 per one million population per year, and out of which only $12 \%$ is contributed by doctors really needs an investigation. This is so, especially when no work has been done to study the rate of reporting ADRs by healthcare professionals in Ghana. Under-reporting is the biggest challenge of spontaneous reporting of ADRs and any study to ascertain the causes and possible resolution to such hindrances is a study in the right direction and purpose of good pharmacovigilance practice.

In this paper, attempt will be made to summarize the article at hand and assay whether the methods or structure of the study and article achieved its aim. This review will also scrutinize the accuracy, currency, authority and the objectivity of the claims made per the information gathered against the prevailing situation. Relevant changes or happenings in the area of ADR reportage since the article 
Texila International Journal of Clinical Research

Volume 3, Issue 2, Dec 2016

publication would be highlighted, and suggest areas where additional research findings would help the understanding of reporting of ADRS.

\section{Review of literature}

ADR reporting is a significant public health issue and of a concern to the pharmaceutical industries and their regulators. Spontaneous reporting of ADRs is a fundamental tool widely used to the success of pharmacovigilance activities all over the world (1). The WHO Program for International Drug Monitoring (PIDM) sets the optimal rate of ADR reporting at over 200 reports per million inhabitants per year (2). Some developed countries in Europe like UK, Sweden, Australia, France and Denmark fall within the range of 300-500 per year $(3,4)$ whiles developing countries such as Ghana has as low as 6.

From this recorded reportage, the healthcare team is expected to contribute the majority. Whiles some countries have quite an open and easy system of reporting where the general public or patients could report, it is not so in less developed countries. The contribution of the healthcare professionals is hugely significant, and cannot be overemphasized (5). In countries where the spontaneous reports has been low, like Africa, the expectation is that the healthcare team would adequately lead the campaign and act accordingly but this has not been the case. Though no work has been done yet in Ghana for a thorough rate of reporting by healthcare professionals, some studies in Nigeria have suggested records of between $2-32 \%$ of the spontaneous reports in that country to be from health professionals $(6,7)$.

The reality of the case therefore suggests that there is generally under-reporting of ADRs and the healthcare professionals are the group from which measures must be addressed to correct this appalling situation. Inman (8) in his popular study has described some of the factors, mostly attitudinal, contributing to such under-reporting of ADRs where he captures them as the "seven deadly sins". These "sins" could be grouped into those bothering on the profession (rewards and financial incentives, litigations and ambition to publish cases) and, knowledge and attitude (complacency, ignorance, indifference and diffidence).

The above literature has been significantly referred to because of their empirical impact on the study conducted in the article.

\section{Article summary}

The primary essence of the study was to measure the frequency with time of reporting adverse drug reaction by medical doctors as part of the health professionals in Greater Accra region of Ghana. Certain factors and attitudes influence the responsibility of the doctors in reporting ADRs, the article sought to identify some these factors and attitudes.

The study suggests that prior training of a medical doctor in reporting would influence the tendency to report a case of adverse event. And it was shown in the study that majority of the doctors were not trained in ADR reportage as against only $27 \%$ trained ones, who were from the government or quasigovernment hospitals. A doctor's participation in clinical research or the number of patient seen per day did not have significant influence on reporting. However, the longer number of years of practice than as a house officer is likely to influence spontaneous reporting.

Almost all (96\%) all of the doctors agreed that they were the most responsible professional to report ADR, lack of time, the commonness or unserious nature of the ADR and the non-availability or inaccessibility of reporting forms could not make them report even with the least chance of having an individual case.

Training and refresher courses be embarked on by the Pharmacovigilance Centre, and report forms be made available and accessible to the doctors. Acknowledgment of receipt and feedback on submitted report could improve the rate of reporting. 


\section{Article structure}

The article was introduced with a summary which comprised of a background to the topic revealing the aim of the study and the need for the research. The method used for the collection of data and the type was also described including the type of statistics or data analysis; descriptive, frequencies and percentages. The results of the research was captured briefly in the summary mostly stating the status of the outcome measures in percentages, then the conclusion of the article was abridged and simplified into the summary.

The main body of the article was arranged under 5 headings; the introduction, methods, results, discussion and conclusion. The introduction was carefully arranged under four-paragraphed thematic areas the history of the subject in literature, the challenge(s) of the subject, the situation in other continents and neighboring countries and the possible causes. The objectives of the study was added to conclude the introduction section.

The methods of the study were described in details under subheadings ranging from the study design and location, sampling, data collection and quality control, data processing and analysis and ethical considerations. This is a well-structured format for revealing the methodology for the study. The results from the data processing and analysis was comprehensibly laid out in three well-arranged tables for easy inferencing and a figure to display the reasons for reporting ADRs.

The discussion of the results of the study was on point in few paragraphs though covered all the measuring outcomes. It covered the impact of the background and knowledge of the doctors on ADR report. The discussion also covered whether the type of hospital facility and the experience of the doctors had impact on the likelihood to report. The conclusion was however very short but fairly on point. The references followed which were chronological arranged in the Modern Language Association format.

\section{Article critique}

\section{Authority}

The Ghana Medical Journal is a quarterly peer-reviewed journal for the Ghana Medical Association but opened to all aspects of health with readership including students, researchers, other health care professionals, policy makers, pharmaceutical representatives, press and the public. The Lancet is a partner and the texts are also available online at African Journal Online and PubMed Central.

The corresponding author is a researcher with the Food and Drugs Authority in Ghana in the Safety Monitoring and Clinical trials Division. He has this and other articles cited by other publications on similar subjects and the contributing authors are known researchers especially Dodoo A.N., so credibility of the authors is thus established.

\section{Accuracy}

The publication of the article was based on a current research work its position is supported by the other current research information and literature review in the article. The article was also published in a peer-reviewed journal which contributed in the accuracy of the article. The references used in the article were fairly current, accurate and well related to the subject of the study.

\section{Currency}

The data for the research work was collected in 2012 and the article published in 2014 and so could be described as current. The year of publication of the reference used ranges from 1998 to 2011. Per the prevailing conditions of the practices spontaneous reporting, not so much has changed from the articles results. The article generally reflects the reality of the current situation in Ghana.

\section{Relevance}

This article's aims are targeted at a real challenge of pharmacovigilance and to some extent in public health. Under-reporting of ADRs and the apathy of doctors regarding spontaneous reporting of 
Texila International Journal of Clinical Research

Volume 3, Issue 2, Dec 2016

ADRs challenges the monitoring of drugs in Ghana. It is therefore relevant to have the content of the article to educative the doctors of what the reality of ADR reporting. Individually the doctor may know the situation as it pertains to their facility but such a study has painted a bigger picture of it.

The content of the article is also relevant to other health care professionals, regulators, policy makers (health ministry), and heads of health institutions as well as the general public. Through this study, the trainings on spontaneous reporting could be intensified and possibly influence other decisions such as empowering other health professionals to report ADRs even from the time of professional training. The article is therefore also relevant for the academicians, and health practice and clinical researchers.

\section{Objectivity}

The article was well written and the data objectively collected based on current practices regarding the subject. Doctors were selected randomly involving the government and private practitioners, specialists to house officers and both genders. The methods employed and the tools for the processing of the data as well as its analysis contributed to the objectivity. Fairly there was minimal introduction of bias though the study could have increased the scope of the sample from just one capital region to others farther from the south.

Per the kind of data collected, the author objectively treated and analyzed them and discussed the results without being bias. Relevant references quoted by the article and the similarities in the outcome measures also supported this claim of the article being objective. The authors however did not state any limitation to the study conducted in their article.

Limitations like the simple random selection of the participant could affect the results of the survey. The claim by the doctors who reported ADR could not be verified or compared with the reality per the data from the National Pharmacovigilance Centre and this is a limitation which can affect the results. The questionnaires could have been sent via mail and the responds sent likewise so that more time could have been used to respond instead of the rush in responding, but it is understandable if the purpose was to improve responds rate.

\section{Stability}

The Ghana Medical Journal, African Journal Online and PubMed are authentic and reliable journals whose contents can be deemed stable. The stability is further entrenched by the articles data collection being based on practice oriented settings.

\section{Analysis of graph/tables}

The article had three different tables and a graph covering outcome measures from background of the participating doctors, their training in spontaneous reporting, the Odds ratios of ADR reporting and their reasons for not reporting ADRs seen.

There were thrice as much doctors below the age 40years than those above. More than half of the respondents were Medical Officers (52.5\%) with the rest being specialist and house officers, and $50.2 \%$ were from teaching hospital level and again 50\% saw between 25-44 patients per day. Approximately $66 \%$ had less than 8years practice experience and $77 \%$ working for the government.

The quasi-government facilities had more doctors among them trained in ADR reporting (approx. $40 \%$ ) than their government counterparts (26\%), with the private sector doctors reporting as low as $11 \%$. The most significant factors for the participating doctors not reporting seen ADRs are nonavailability of the reporting forms and ignorance of the reporting procedures.

\section{Recent advances related to the topic}

Searching through online journals in PubMed for "spontaneous reporting of ADR" or "adverse drug reaction reporting", many article were sited with similar conclusions of lack of knowledge or ignorance of procedures for spontaneous reporting by various health professionals worldwide except for well developed countries. 
Akshaya et al. (2016) through a systemic review suggested that pharmacovigilance activities in India was low and as huge as $75 \%$ of had never reported any ADR and that there was a big polarity in terms of knowledge, attitude and practice against pharmacovigilance activities (9).

According to Yun Mi Yu et al. (2016), the rate of spontaneous report by community pharmacist in Korea was as high as $95 \%$ and this could be attributed to the continuous education and training of health professionals about ADR reporting and their experiences with ADR cases. According to the article, these professionals do not allow or were less concerned about the obstacles to reporting (10). Similarly in Malesia, other health professions aside doctor and pharmacist, like nurses, were assigned more responsible roles of reporting ADRs especially those pertaining to vaccines. This contributed to a steep rise in ADR reports with respect to children (11). There are other initiatives by some countries to increase rates of spontaneous reporting.

In Turkey, there has been a gradual increase in reporting rates due to the increased awareness of pharmacovigilance activities and introduction of the practice of having a pharmacovigilance contact points (PvCPs, a physician/pharmacist) in the various hospital facilities to champion the course of ADR reporting.

Other initiatives like the establishment of pharmacovigilance inspections in the health facilities and the empowerment of the patients to also report directly to the pharmacovigilance centers which is already available in certain European countries like Denmark, Sweden, Australia and Netherlands (12, 13). In relation to the involvement of the public in reporting is the initiative of incorporating technological tools to the usual reporting forms. This will be in the interest of both the public and the health care professional alike with the use of texting-based ADR reporting system or smart phones and through other form of internet communications $(14,15)$.

The pharmacovigilance activities in Africa is still in its development and there more non-member state to the international monitoring program to join this all important program. There are more interventional measures to be undertaken to correct the under-reporting of ADRs by just studying the above sited literature (16).

\section{Conclusion}

The article by Sabblah et al. "Adverse drug reaction reporting by doctors in a developing country: a case study from Ghana”, generally was well written, arranged and results objectively discussed. This review was to summarize and critique the content of the study and state possible recommendations. In the article there were no recommendations or limitation to the study itself, recommendations were however made for improving spontaneous reporting. The results cannot be generalized so further studies are recommended in a national scope. There are new national campaigns where patients are encouraged to report ADR especially to community pharmacies, so it will be interesting to test the impact and the rate of reporting from the pharmacist perspective. This review has to some extent added some value to scientific literature by the constructive critique of a study on ADR spontaneous report.

\section{References}

[1.] Aagaard L, Stenver DI, Hansen EH. (2008) Structures and processes in spontaneous ADR reporting systems: a comparative study of Australia and Denmark. Pharm. World Sci. 30(5):563-570. Doi: 10.1007/s11096-008-9210-y https://www.ncbi.nlm.nih.gov/pubmed/18350372

[2.] Ahmad SR. (2003) Adverse drug event monitoring at the Food and Drug Administration. J Gen Intern Med. 285:437-443 https://www.ncbi.nlm.nih.gov/pmc/articles/PMC1494803/

[3.] Akshaya Srikanth Bhagavathula, et al. (2016) Health Professionals' Knowledge, Attitudes and Practices about Pharmacovigilance in India: A Systematic Review and Meta-Analysis. PLoS One, 11(3): e0152221. doi:10.1371/journal.pone.0152221 https://www.ncbi.nlm.nih.gov/pmc/articles/PMC4807086/

[4.] Blenkinsopp A, Wilkie P, Wang M, Routledge PA. (2007) Patient reporting of suspected adverse drug reactions: a review of published literature and international experience. Br J ClinPharmacolFeb;63(2):148-156. 
Texila International Journal of Clinical Research

Volume 3, Issue 2, Dec 2016

DOI:

10.1111/j.1365-2125.2006.02746.

http://onlinelibrary.wiley.com/doi/10.1111/j.1365-

2125.2006.02746.x/full

[5.] Belton KJ. (1997) Attitude survey of adverse drug reaction reporting by health care professionals across the European Union. The European Pharmacovigilance Research Group. Eur. J. Clin. Pharmacol 52(6):423-7. https://www.ncbi.nlm.nih.gov/pubmed/9342576

[6.] Bello SO, Umar MT.(2011) Knowledge and attitudes of physicians relating to reporting of adverse drug reactions in Sokoto, north-western Nigeria. Ann Afr Med 10(1): 13-18. Available from: http://www.annalsafrmed.org/article.asp?issn=1596-

3519; year=2011; volume=10;issue $=1$; spage $=13$; epage $=18$; aulast $=$ Bello

[7.] Enwere OO, Fawole OI. (2008) Adverse drug reactions reporting by physicians in Ibadan, Nigeria. Pharmacoepidemiology and Drug Saf. 17:517-522. https://www.ncbi.nlm.nih.gov/pubmed/18404621/

[8.] GulnihalOzcan, (2016) Adverse Drug Reaction Reporting Pattern in Turkey: Analysis of the National Database in the Context of the First Pharmacovigilance Legislation. Drugs Real World Outcomes, Mar; 3(1): 33-43.doi: 10.1007/s40801-015-0054-1 https://www.ncbi.nlm.nih.gov/pmc/articles/PMC4819489/

[9.] Haggar H. Ampadu et al. (2016) Adverse Drug Reaction Reporting in Africa and a Comparison of Individual Case Safety Report Characteristics Between Africa and the Rest of the World: Analyses of Spontaneous Reports in VigiBase ${ }^{\circledR}$. Drug Saf, 39: 335-345. doi: 10.1007/s40264-015-0387-4 https://www.ncbi.nlm.nih.gov/pmc/articles/PMC4796322/

[10.] Inman WH. (1996) Attitudes to adverse drug-reaction reporting. $\mathrm{Br} J$ ClinPharmacol 41:433-5. https://www.ncbi.nlm.nih.gov/pubmed/8735689/

[11.] JoëlleBerrewaerts et al. (2016) Patient Participation and the Use of Ehealth Tools for Pharmacovigilance.

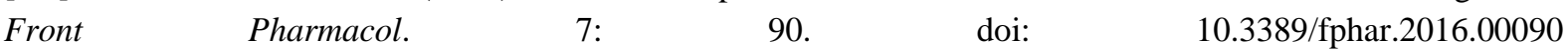
https://www.ncbi.nlm.nih.gov/pmc/articles/PMC4827142/

[12.] Pal S et al. (2011) The world medicines situation 2011: Pharmacovigilance and safety of medicines. Geneva: WHO, 2011 [cited 2016, 23 September]. Available from: http://apps.who.int/medicinedocs/documents/s18771en/s18771en.pdf

[13.] RoslianaRosli (2016) A Retrospective Analysis of Spontaneous Adverse Drug Reactions Reports Relating to Paediatric Patients. PLoS One, 11(6): e0155385. doi: 10.1371/journal.pone.0155385 https://www.ncbi.nlm.nih.gov/pmc/articles/PMC4889073/

[14.] The WHO Pharmacovigilance Reporting Trends. [Cited 2016, September 2016].Available from: http://www.whoumc.org/DynPage.aspx?id=108476\&mn1=7347\&mn2=7252\&mn3=7322\&mn4=7558

[15.] Vergeire-Dalmacion G, Castillo-Carandang NT, Juban NR, Amarillo ML, Tagle MP, Baja ES (2015) Texting-Based Reporting of Adverse Drug Reactions to Ensure Patient Safety: A Feasibility Study. JMIR Public Health Surveill, Jul-Dec; $\quad 1(2): \quad$ e12 $\quad$ DOI: $10.2196 /$ publichealth.4605 https://www.ncbi.nlm.nih.gov/pmc/articles/PMC4869238/

[16.] Yun Mi Yu et al. (2016) Predictive Factors of Spontaneous Reporting of Adverse Drug Reactions among Community Pharmacists. PLoS One, 11(5): e0155517. doi: 10.1371/journal.pone.0155517 https://www.ncbi.nlm.nih.gov/pmc/articles/PMC4871451/ 